Editorial

\title{
50 anos da Sociedade Brasileira de Hematologia e Hemoterapia
}

\author{
Celso Carlos de Campos Guerra
}

Em maio de 2000 foi comemorado o Jubileu de Ouro da Sociedade Brasileira de Hematologia e Hemoterapia. Foram 50 anos de intensa atividade no aprimoramento das nossas especialidades e no desenvolvimento dos médicos para melhor atender a seus pacientes.

Já na sua fundação, os participantes decidiram por uma Sociedade que englobasse a Hematologia e a Hemoterapia. Tiveram a percepção do íntimo relacionamento que veio a se concretizar nestes 50 anos. A SBHH cumpriu o seu papel, aglutinando os médicos que escolheram o sangue como seu objetivo.

Realizou 25 congressos nacionais, inúmeras jornadas, simpósios e cursos procurando reciclar os especialistas para melhor desempenho de suas atuações.

Ao criar os Títulos de Especialista em Hematologia e Hemoterapia, consolidou a profissão no cenário médico nacional.

Com os títulos de proficiência abre um estímulo para os profissionais de nível universitário aprimorarem seus conhecimentos.

A edição de uma Revista de Hematologia e Hemoterapia permite a divulgação dos trabalhos científicos produzidos no Brasil para conhecimento dos médicos especialistas. 0
HemoNews leva aos sócios notícias breves do que acontece na área.

Leva à comunidade e com ela interage, ao terminar com a doação remunerada de sangue. Participa de campanhas para doação voluntária e para esclarecimentos à população como a Cruzada contra a Anemia.

Colabora ativamente em várias Comissões ligadas ao Ministério da Saúde na área de sangue, levando sua experiência e espírito crítico.

Estimulou, patrocinou e cooperou na formação de protocolos para tratamento da leucemia aguda na infância, que colocou 0 Brasil no mesmo nível de países desenvolvidos pelo bom resultado alcançado.

Estimula e colabora na melhoria da qualidade do sangue com o Programa de Controle Externo em Sorologia e de Imunohematologia.

Ajuda a introduzir uma moderna gestão com o Sistema da Qualidade em Hemoterapia.

Cria instrumentos para aferir esta qualidade, como o Programa de Acreditação das Unidades Hemoterápicas.

Assim, podemos constatar que a SBHH teve passado, tem presente e certamente com 0 trabalho de todos, terá futuro. 